\title{
High Frequency of Tc22 and Th22 Cells in Myasthenia Gravis Patients and Their Significant Reduction after Thymectomy
}

\author{
Behrouz Robat-Jazi ${ }^{\mathrm{a}}$ Mina Hosseini $^{\mathrm{a}}$ Vahid Shaygannejad $^{\mathrm{b}}$ Shahriar Nafissi $^{\mathrm{c}}$ \\ Abbas Rezaei $^{a}$ Marjan Mansourain ${ }^{d}$ Omid Mirmosayyeb ${ }^{\mathrm{e}}$ Nafiseh Esmaeil $^{\mathrm{a}}$ \\ a Department of Immunology, School of Medicine, Isfahan University of Medical Sciences, Isfahan, Iran; \\ ${ }^{\mathrm{b}}$ Isfahan Neurosciences Research Center, Alzahra Hospital, Isfahan, Iran; 'Department of Neurology, \\ Iranian Center for Neurological Research, Shariati Hospital, Tehran University of Medical Sciences, Tehran, Iran; \\ ${ }^{\mathrm{d}}$ Department of Biostatistics and Epidemiology, School of Health, Isfahan University of Medical Sciences,

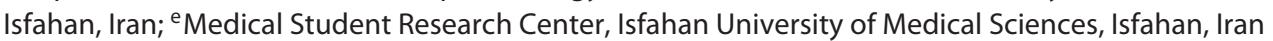

\section{Keywords}

Myasthenia gravis · Thymectomy · Th22 cells · Tc22 cells

\begin{abstract}
Objectives: Myasthenia gravis (MG) is an autoimmune disease accompanied by a thymic pathology and in most patients thymectomy (TE) is used as the therapeutic approach. Both $B$ and T cells play an important role in MG pathogenesis. Methods: Twelve pre- and post-TE MG patients and 12 healthy controls (HCs) were enrolled. The mean percentages of Th22 and Tc22 cells were evaluated in MG patients (before and 6 months after TE) and HCs. Results: The mean percentage of Tc22 cells in pre-TE patients was significantly higher than in HCs $(p<0.05)$, and after TE Tc22 cells significantly decreased compared to pre-TE $(p<0.05)$. The frequency of Th22 cells in pre-TE MG patients was not significantly different from HCs, but after TE Th22 cells were significantly decreased compared to pre-TE $(p<0.05)$. Conclusion: Our findings suggest a possible role of Th22 and Tc22 in MG pathogenesis.

(c) 2018 S. Karger AG, Basel
\end{abstract}

\section{Introduction}

Myasthenia gravis (MG) is an autoimmune disorder commonly caused by antibodies against the acetylcholine receptor (Achr) and skeletal muscles [1]. Although these antibodies are secreted by B lymphocytes of the immune system, CD4+ T lymphocytes (T-helper cells) identify Achr as a dominant immune epitope which causes MG disease progression [2, 3]. Also, MG disease is usually accompanied by thymus gland abnormalities, such as hyperplasia $(65 \%)$ or thymoma $(10-15 \%)[4,5]$, and treatment can be conducted in both a medical and surgical manner [6]. Accordingly, complete removal of the thymus (thymectomy; TE) is one treatment method in $M G$ patients $[7,8]$. The thymus as a central lymphoid organ plays an important role in central immune tolerance which regulates non-self-reactive $\mathrm{T}$ cells and removes self-autoreactive T cells [9]. Studies have shown that in MG patients the thymus contains a number of $\mathrm{B}$ lymphocytes which produce autoantibodies against the Achr in culture and increased production of this anti-

\section{KARGER}

(c) 2018 S. Karger AG, Basel

E-Mail karger@karger.com

www.karger.com/nim
Nafiseh Esmaeil, PhD

Department of Immunology, School of Medicine

Isfahan University of Medical Sciences

Isfahan 81744-176 (Iran)

E-Mail nafesm5@gmail.com 
body is induced by T-helper cells. So, both B and T lymphocytes which pass from the thymus play a major role in the pathogenesis of the disease $[10,11]$.

Over the past few years, due to different cytokine secretion patterns and diverse immune performance, the diversity of TCD4+ cells was limited to T-helper 1 and T-helper 2 cells $[12,13]$. Th22 is another subgroup of TCD4+ T-helper cells which was mentioned recently by Trifari et al. [14] in 2009. Th22 cells do not secrete interleukin 17 (IL-17) or interferon- $\gamma$ (IFN- $\gamma$ ), but secrete large amounts of IL-22 and tumor necrosis factor-alpha (TNF- $\alpha)[14,15]$. These cells express chemokine receptor CCR6, and also implantation receptors in the skin such as CCR4 and CCR10. The main transcription factor of Th22 cells is the Aryl hydrocarbon receptor, AHR [15]. Overall, valid scientific signs prove that Th22 cells are expressed independently in subgroups of the $\mathrm{T}$ cell line $[15,16]$. Except for TCD4+ cells, CD8+ T cells may also secrete IL-22. CD8+ T cells that secrete IL-22 are also known as Tc22 cells [17]. The role of Th22 cells in the pathogenesis of many autoimmune diseases has been shown [16, 18-21]. Vitales-Noyola et al. [22] indicated that both Th22 and Th17 cells are involved in the pathogenesis of autoimmune thyroid disorders and showed significant correlations between the levels of these cells and disease activity. In systemic lupus erythematosus, the contribution of Th22 cells in the pathogenesis of patients with skin or renal impairment has been described [23]. In addition, skin-homing Th22/Tc22 cells in atopic dermatitis and psoriasis have been found in previous studies $[18,24]$.

As mentioned above, MG is an autoimmune disease and the role of the thymus gland related to the autoimmunity of this disease has been identified. On the other hand, the thymus gland has roles in positive and negative selection and self-reactive $\mathrm{T}$ cell removal. Many studies have shown that Th22 and Tc22 cells as a subgroup of T-helper cells have an important role in the pathogenesis of many autoimmune diseases. Therefore, the aim of this study was to survey frequency changes of Th22 and Tc22 cells, and the ratio of these cells in MG patients before and after of TE compared to healthy controls (HCs).

\section{Materials and Methods}

\section{Study Subjects and Sample Collection}

In the present study, we sought to monitor the development of Th22 and Tc22 lymphocyte subpopulations in the peripheral blood of healthy subjects and MG patients before and 6 months

Table 1. Clinical characteristics of the MG patients

$n$

Female/male, $n$

Disease duration before TE (range), years

Medication before TE

Mestinon, mg/day

Medication after TE

Mestinon, mg/day

Age at time of thymectomy, years

Serum anti-AChR Ab positive

Thymus pathology

Thymoma

Thymic hyperplasia

MG severity before TE

$\begin{array}{ll}\text { IIa } & 2(16.6) \\ \text { IIb } & 3(25) \\ \text { III } & 5(41.6) \\ \text { IV } & 2(16.6)\end{array}$

Data are presented as the mean (range), $n$ (number), and percentage. MG, myasthenia gravis; TE, thymectomy.

after TE. We recruited $12 \mathrm{MG}$ patients from Shariati Hospital (Tehran, Iran) and Alzahra Hospital (Isfahan, Iran), and 12 ageand sex-matched HCs from the outpatient service of our institution (Department of Immunology, Isfahan Medical School, Isfahan, Iran) from April 2016 to May 2017. The patients all had clinical and electrophysiological evidence of MG. Not all patients had positive titers of AChR antibodies. Histopathologic assessment of the thymus was performed on all specimens, which were also confirmed by a pathologist.

Patients with the following characteristics were excluded: (1) accompanied by other autoimmune diseases such as Graves' disease or systemic lupus erythematosus, (2) pregnancy or lactation, and (3) ocular MG without generalized weakness. HCs did not have any signs of autoimmune diseases or a family history of MG, and did not take any immunomodulatory or immunosuppressive drugs. The informed consent of all participating subjects was obtained according to the Ethics Committee of the Isfahan University of Medical Sciences. For all subjects, blood samples were collected and peripheral blood mononuclear cells (PBMCs) were isolated and separated by Ficoll-Hypaque gradient centrifugation (Inno-Train, Germany).

Stimulation of PBMCs for Cytokine Responses

PBMCs were incubated with phorbol 12-myristate 13-acetate (PMA; $25 \mathrm{ng} / \mathrm{mL}$, Sigma-Aldrich, USA) plus ionomycin $(1 \mu \mathrm{g} / \mathrm{mL}$, Abcam, USA $)$ in the presence of monensin $(0.35 \mathrm{mg} / \mathrm{mL}$, BioLegend, USA), and brefeldin A ( $0.75 \mathrm{mg} / \mathrm{mL}$, eBioscience, USA) for 5 $\mathrm{h}$ at $37^{\circ} \mathrm{C}$ to induce cytokine responses.

\section{Cell-Surface and Intracellular Staining on PBMCs}

After incubation, the cells were divided into 2 tubes and stained with anti-CD3FITC, anti-CD4PE, and anti-IL-22PECY7 in 1 tube and with anti-CD3FITC, anti-CD8PE, and anti-IL- 
Table 2. Real values of Th22 and Tc22 cell subsets in MG patients before and after TE, the reduction in anti-AChR Ab titer after TE, and thymic pathology

\begin{tabular}{lllll}
\hline Patient No. & $\begin{array}{l}\text { Th22 } \\
\text { before/after, } \%\end{array}$ & $\begin{array}{l}\text { Tc22 } \\
\text { before/after, } \%\end{array}$ & $\begin{array}{l}\text { Decreased anti-AChR } \\
\text { Ab titer after TE, \% }\end{array}$ & $\begin{array}{l}\text { Thymic pathology } \\
1\end{array}$ \\
\hline $2.43 / 1.10$ & $0.89 / 0.37$ & 31.25 & $\begin{array}{l}\text { Thymic hyperplasia } \\
\text { Thymic hyperplasia }\end{array}$ \\
3 & $2.21 / 0.95$ & $0.92 / 0.42$ & 29.7 & Thymic hyperplasia \\
4 & $1.89 / 1.04$ & $0.99 / 0.54$ & 16 & Thymic hyperplasia \\
5 & $2.01 / 1.06$ & $1.05 / 0.48$ & Negative & Thymic hyperplasia \\
6 & $0.90 / 0.98$ & $0.81 / 0.58$ & 20 & Thymoma \\
7 & $1.15 / 1.18$ & $1.14 / 0.62$ & 28.6 & Thymic hyperplasia \\
8 & $1.68 / 1.54$ & $1.24 / 0.89$ & 33.4 & Thymic hyperplasia \\
9 & $1.74 / 1.01$ & $0.88 / 0.75$ & 39.3 & Thymoma \\
10 & $2.31 / 0.91$ & $1.11 / 0.68$ & Negative & Thymic hyperplasia \\
11 & $1.78 / 1.20$ & $1.01 / 0.90$ & 33.4 & Thymoma \\
12 & $1.65 / 1.20$ & $0.87 / 1.09$ & 10 & Thymic hyperplasia \\
\hline
\end{tabular}

MG, myasthenia gravis; TE, thymectomy; Ab, antibody.

Fig. 1. CD4 and CD8 T cells in MG patients (before and after TE) and controls. a, b Significantly elevated percentages of CD4 and CD8 T cells were found in MG patients compared to $\mathrm{HCs}(p=0.013$ and $p=0.001$, respectively). Also, the percentages of the CD4 and CD8 cells among lymphocytes were significantly decreased in MG patients when compared with those measured 6 months after TE $(p<0.0001$ and $p=0.011$, respectively). ${ }^{*} p<0.05,{ }^{* *} p<$ $0.01,{ }^{* * *} p<0.001$.

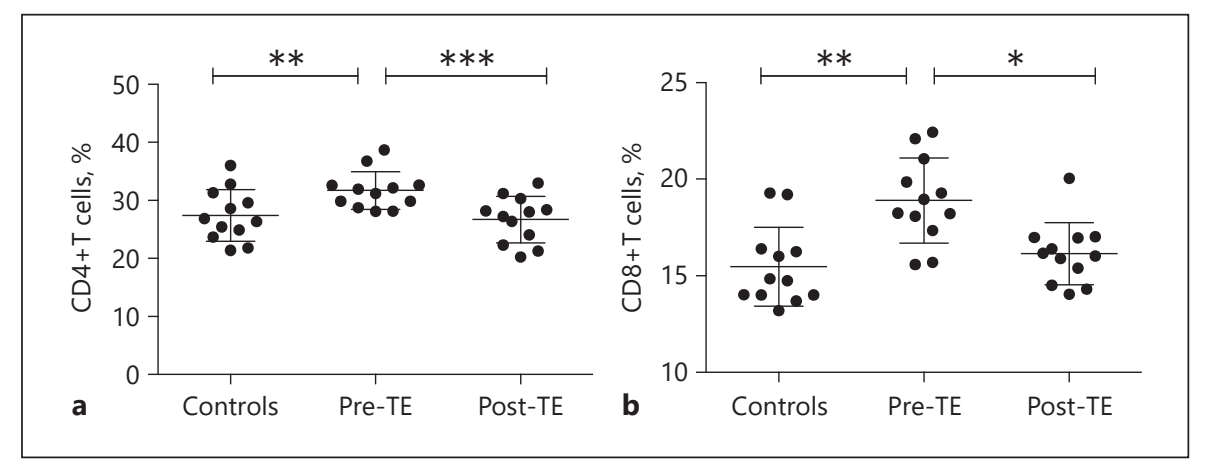

22PECY7 in another tube for $30 \mathrm{~min}$ at $4{ }^{\circ} \mathrm{C}$. After surface staining, fixation and permeabilization were performed according to the manufacturer's instructions (eBioscience), and the cells were stained with PE-Cyanine7 conjugated anti-IL-22 monoclonal antibodies. Isotype controls were given to enable the correct compensation and confirm antibody specificity (all antibodies were bought from eBioscience). Stained cells were analyzed by flow cytometric analysis using a FACS Caliber cytometer equipped with CellQuest software (BD Bioscience Pharmingen, San Jose, CA, USA).

\section{Statistical Analysis}

Statistical analysis was performed by SPSS version 24 . In order to compare pre-TE MG patients to the control group, an independent $t$ test was used and the paired Student $t$ test was performed for pre- and post-TE MG patients. The results are reported as the $p$ values. The normal distribution of data was studied by Kolmogorov-Smirnov. The interrelationship between the 2 parameters was tested by Pearson correlation analysis. $p<0.05$ was considered significant.

\section{Results}

\section{Patient Characteristics}

The clinical characteristics of the MG patients are presented in Table 1 . Three of the 12 patients had thymoma and 9 had thymus hyperplasia. The responses of the 2 groups to TE were very similar and the titer of anti-AChR antibody was decreased in all antibody-positive patients (Table 2).

\section{High Frequency of CD4+ and CD8+ T Cells in $M G$}

Patients Were Decreased after TE

The frequency of the CD4 and CD8 cells among lymphocytes significantly increased in MG patients compared to the HCs $(p=0.013$ and $p=0.001$, respectively; Fig. 1a, b). Also, the percentage of the CD4 and CD8 cells among lymphocytes was significantly decreased in $\mathrm{MG}$ 

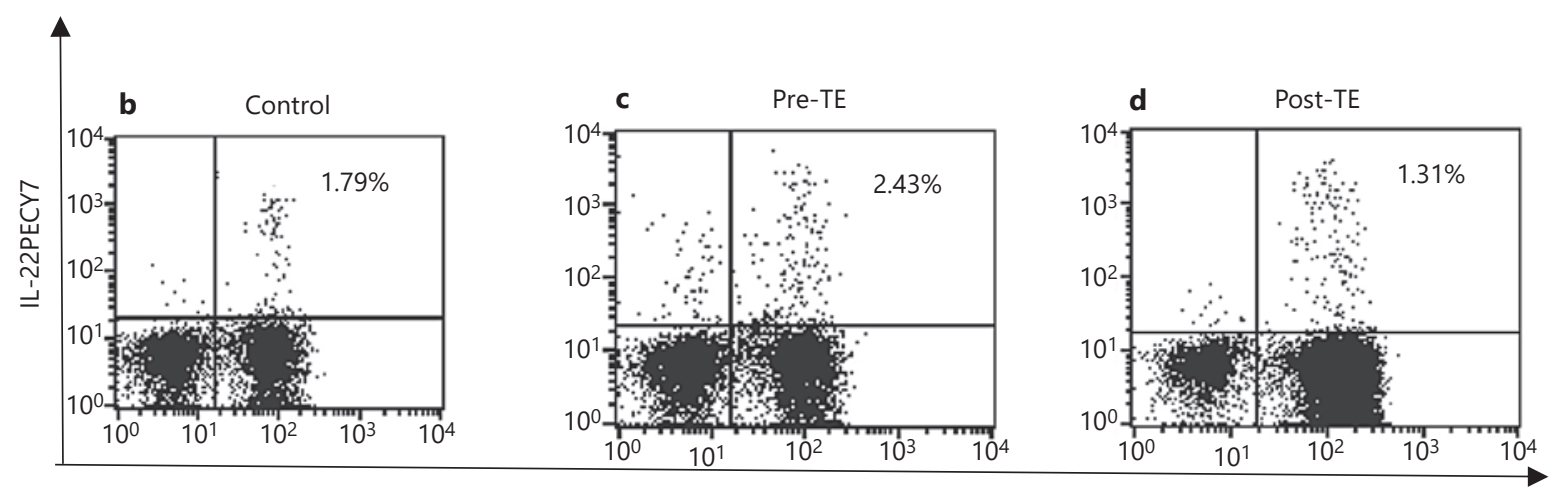

CD4-PE
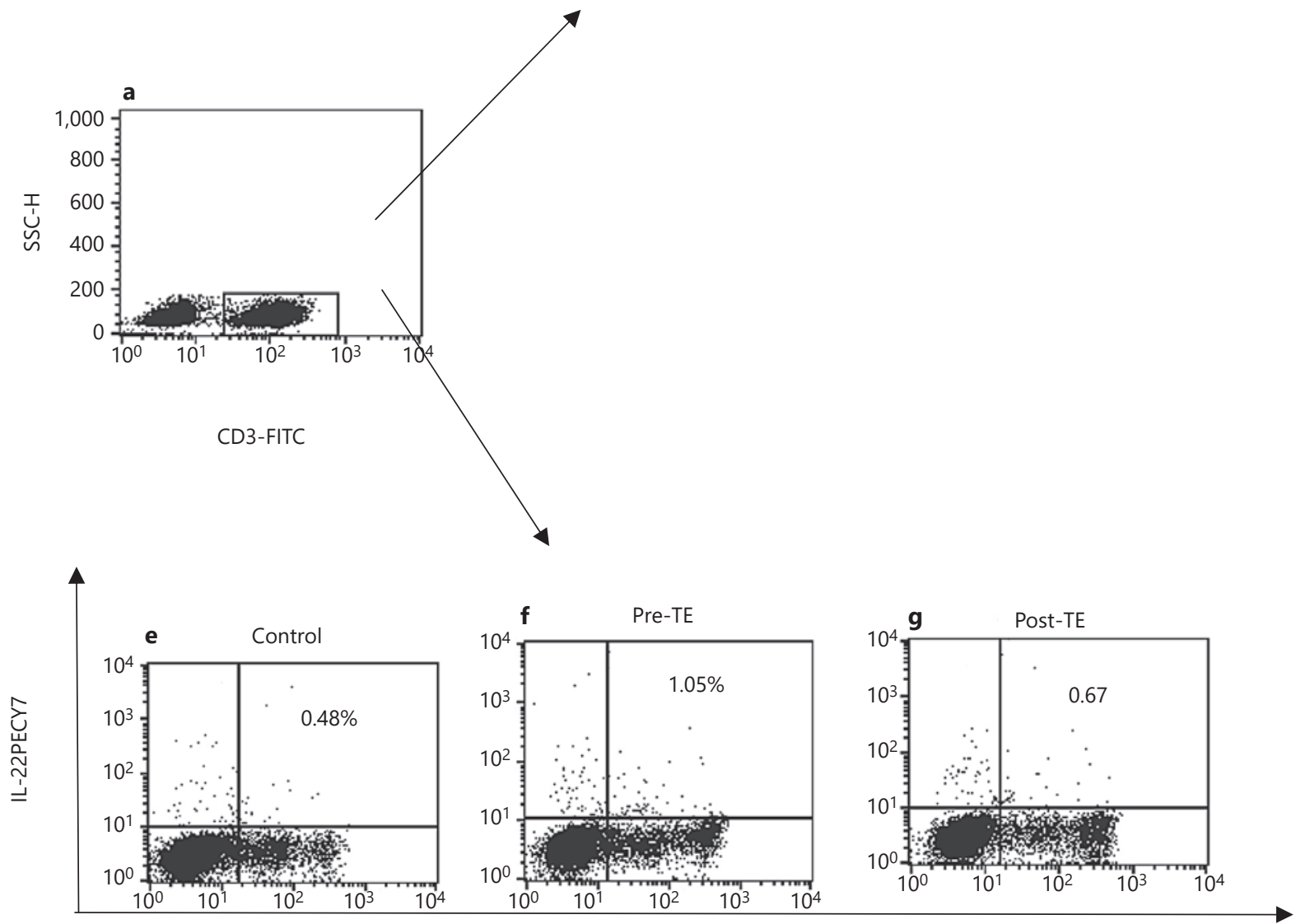

CD8-PE

Fig. 2. The percentages of circulating Tc22 and Th22 cells in controls and MG patients (before and after TE). Heparinized peripheral whole blood from all subjects was stimulated with phorbol myristate acetate, ionomycin, brefeldin, and monensin for $5 \mathrm{~h}$, then stained with labeled antibodies as described in Materials and
Methods. a CD3+ T subsets were gated by flow cytometry. b The percentages of circulating Th22 cells from controls. c, d MG patients before and after TE. e The percentages of circulating Tc22 cells from controls. f, $\mathbf{g}$ MG patients before after TE. Positive cells are shown in each panel. 


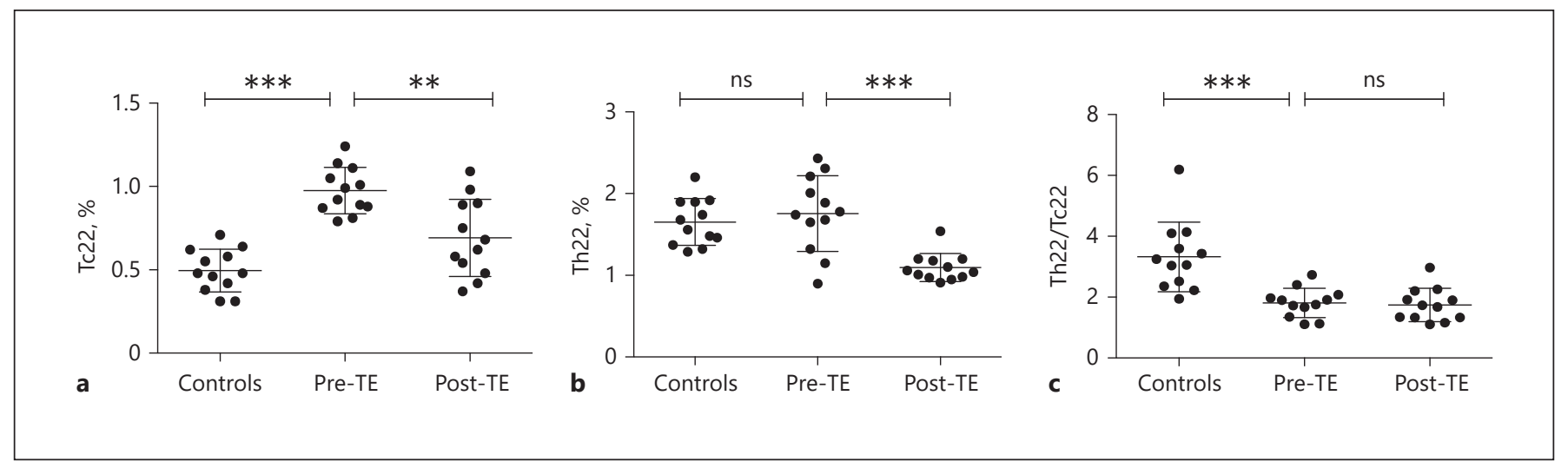

Fig. 3. Tc22 and Th22 cells, and the Th22:Tc22 ratio in controls and MG patients (before and after TE). a Significantly elevated percentages of Tc22 were found in MG patients (mean $0.97 \%$, range $0.79-1.24 \%, p<0.0001$ ) compared to HCs (mean $0.49 \%$, range $0.31-0.64$ ) and the percentages of these cells were significantly decreased after TE (mean $0.97 \%$, range $0.79-1.24 \%, p=$ 0.004 ) compared to before TE (mean $0.69 \%$, range $0.37-1.09 \%$ ). b Statistically elevated percentages of Th22 cells were found in MG patients (mean 1.75\%, range $0.9-2.43 \%$ ) compared to after TE (mean $1.09 \%$, range $0.91-1.54 \%, p=0.001$ ), and no significant difference was found in the percentage of Th22 cells in HCs and MG patients. c The T2217:Tc22 ratio in MG patients was 1.76-fold lower than controls $(p=0.0001)$ and there were no significant differences in the Th22:Tc22 ratio in MG patients compared with those measured 6 months after TE $(p=0.665){ }^{* *} p<0.01,{ }^{* * *} p<0.001$.
Fig. 4. a Positive correlation between Th17/ Th22 and Tc17/Tc22 cells in healthy subjects. b Positive correlation between Th17/ Tc17 and Th22/Tc22 cells after TE.

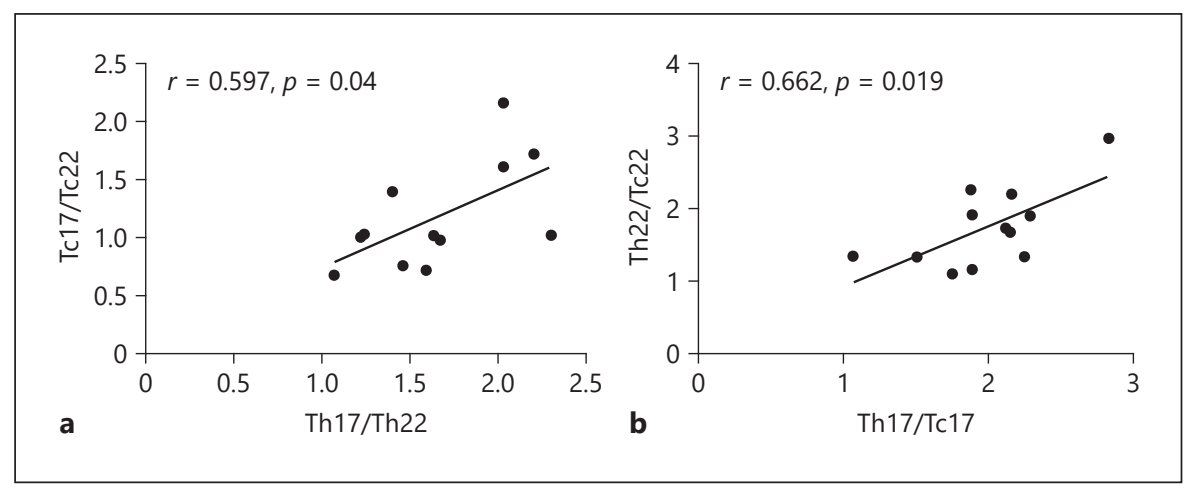

patients when compared with those measured 6 months after surgery $(p<0.0001$ and $p=0.011$, respectively; Fig. 1a, b). We did not observe significant differences between the proportion of the CD4/CD8 cells among lymphocytes in MG patients when compared with those measured 6 months after surgery $(p=0.626)$.

\section{Elevated Tc22 Cells in MG Patients Compared to Healthy Subjects}

We analyzed the frequencies of Tc22 and Th22 cells based on cytokine production after in vitro activation by $\mathrm{PMA} /$ ionomycin in short-term cultures. The expression of a typical dot plot of IL-22 gated on CD3+ T cells in MG patients before TE, post-TE, and HCs is shown in Figure 2.
IL-22 was expressed on CD3+CD4+ and CD3+CD8+ $\mathrm{T}$ cells. Compared with HCs (mean $0.49 \%$, range $0.31-$ 0.64 ), the percentage of Tc22 cells was significantly increased in the MG patients (mean $0.97 \%$, range 0.79 $1.24 \%, p<0.0001$; Fig. 3a). However, there was no significant statistical difference in Th22 frequency between MG patients and HCs (Fig. 3b). As shown in Figure 3c, the Th22:Tc22 ratio in MG patients was 1.76-fold lower than in the HCs $(p=0.0001)$. Also, there was no significant correlation between the decreased percentage of Th22 cells and the decreased percentage of AchoR-Ab titer. 
The Decrease of Th22 and Tc22 Cells in MG Patients after TE

We also assessed the frequency of Th22 and Tc22 cells in MG patients 6 months after TE. Our results showed that Tc22 were decreased significantly in MG patients post-TE (mean $0.69 \%$, range $0.37-1.09 \%$ ) compared to before TE (mean 0.97\%, range $0.79-1.24 \%, p=0.004$; Fig. 3a). We also demonstrated a statistically significant difference in Th22 between MG patients before TE (mean $1.75 \%$, range $0.9-2.43 \%$ ) and post-TE (mean $1.09 \%$, range $0.91-1.54 \%, p=0.001$; Fig. 3b). There were no significant differences in the Th22:Tc22 ratio in MG patients compared with those measured 6 months after TE $(p=0.665)$. Simultaneously with the assessment of Th22 and Tc22 cells, we also analyzed Th17 and Tc17 cells in these patients, the results of which have been published [25]. We found a positive correlation between Th17/Th22 and Tc17/Tc22 cells in healthy subjects $(r=0.597, p=0.04$; Fig. 4a). Also after TE, Th17/Tc17 and Th22/Tc22 cells showed a positive relationship $(r=0.662, p=0.019$; Fig. 4b). However, we did not find any correlation between these ratios in MG patients before TE.

\section{Discussion}

MG is an autoimmune disease mediated by autoantibodies against components of the postsynaptic membrane at the neuromuscular junction [26]. Most MG patients (80-90\%) have a thymic pathology including thymic hyperplasia (the presence of germinal centers containing a large number of B cells) and thymoma (the presence of a tumor), indicating the importance of the thymus in the pathogenesis of MG disease [27, 28]. On the other hand, TE can reduce the severity of disease and also induce remission in most patients, especially in patients with thymic follicular hyperplasia, suggesting a causal correlation between thymic pathology and MG [29]. A transcriptome analysis of the hyperplastic thymus showed signs of inflammation in the thymus but not in the muscle, so the autoimmune response against Achr likely develops in the thymus $[30,31]$. Achr-specific T cells have been observed in the thymus of MG patients and these cells have an important role in activating B cells to produce anti-Achr antibodies [32, 33]. Also, Gradolatto et al. [34] showed that regulatory $\mathrm{T}$ cells are defective in MG and conventional $\mathrm{T}$ cells are resistant to Treg cell suppression. Therefore, due to chronic inflammation in the thymus of MG patients, autoreactive T cells could escape from regulation in the MG thymus.

High Frequency of Tc22 and Th22 Cells

in Myasthenia Gravis Patients
In the present study, we found increased CD4+ and CD8+ $\mathrm{T}$ cells in MG patients compared to HCs, which was significantly decreased when compared with those measured 6 months after TE. The role of CD4+ T cells in the pathogenesis of MG has been indicated in previous studies, and depletion of these cells in AIDS patients has been associated with improvement in MG symptoms [35-37]. Also, studies have shown MG patients with thymoma produce abundant maturing thymocytes and export mature, potentially autoreactive $\mathrm{CD} 4+$ and $\mathrm{CD} 8+\mathrm{T}$ cells $[38,39]$. Buckley et al. [38] showed that neoplastic thymoma tissue itself can generate and export mature, long-lived CD4+ and CD8+T cells. They measured episomal DNA fragments ( $\mathrm{T}$ cell receptor excision circles; TRECs) generated by $\mathrm{T}$ cell receptor gene rearrangement, and found that TREC levels were significantly increased in both the CD4+ and CD8+ peripheral blood compartments of MG patients. Also in their study, TREC levels declined after TE to values similar to the controls. The role of $\mathrm{CD} 8+\mathrm{T}$ cell responses has been indicated in the pathogenesis of multiple sclerosis (MS), in which the $\mathrm{CD} 4+\mathrm{T}$ cell-mediated autoimmune response in fact leads to epitope spreading to antigen-specific CD8+ T cells [40, 41]. According to a study by Tackenberg et al. [42], CD8+ $\mathrm{T}$ cells could contribute to late-onset MG pathogenesis, maybe through a similar mechanism of CD8+ T cell activation in MS patients. Although the high-affinity antiAchr antibodies have the important role in MG pathogenesis, the initiation of these Th-dependent responses and the role of other $\mathrm{T}$ cell subsets such as CD8+ T cells is not yet understood.

To the best of our knowledge, this paper is the first to study Th22 and Tc22 cells in MG patients before and after TE. In the present study, there was no statistical difference in Th22 frequency between MG patients and HCs, while a statistically significant decrease in Th22 was found post-TE. The role of Th2 2 cells in the pathogenesis of autoimmune diseases has been confirmed in many studies [16, 43-47].

Gradolatto et al. [48] showed increased IL-22 gene expression in MG patients, which is consistent with our findings. In contrast, Zheng et al. [49] indicated decreased IL-22 mRNA in PBMCs and IL-22 levels in the serum of MG patients compared to normal controls. IL-22 is a cytokine produced by CD4+ T cells (Th1, Th17, and Th22), NK cells, and NKT cells. Studies have shown a dual role (proinflammatory and regulatory) for IL-22 in inflammation and, accordingly, there are discrepancies in data with the IL-22 role in autoimmune diseases $[50,51]$. In the present study, we assessed CD3+, CD4+, and IL-22+ cells

Neuroimmunomodulation 2018;25:80-88 DOI: $10.1159 / 000490855$ 
as Th22 but, as mentioned earlier, IL-22 also produces by both Th17 and Th1 cells, so a slightly greater percentage of Th22 in MG patients compared to the controls may be due to the high frequency of Th17 and Th1 cells in these patients [48]. Also, recent studies have indicated the role of Th17 and Th22 cells simultaneously in autoimmune and cancer diseases [52-56]. The role of Th17 cells in the induction of ectopic lymphoid follicles within the central nervous system in the animal model of MS has been shown by Zhang et al. [57]. Also, the presence of ectopic germinal centers in the thymus of MG patients has been indicated $[58,59]$. Therefore, although the role of Th22 cells in the induction of ectopic follicles is not known, due to the production of the IL-22 cytokine by these T cells and Th17 cells, it is likely that these 2 cell subsets play a role in the formation of abnormal follicles in the thymus, which requires further studies.

Also, we assessed Th17 and Tc17 cells in these patients, and we found that these cells were elevated in comparison with healthy subjects, and their frequency decreased after TE [60]. Th 22 and Th17 cells express multiple chemokine receptors, including CCR6, CCR4, and CCR10 [61, 62]. These chemokine receptors, especially CCR6, have an important role in Th17 and Th22 cell infiltration into the skin in various skin diseases, such as atopic dermatitis, scleroderma, and psoriasis [63]. Therefore, the decrease of Th22 cells after TE in the present study and improvement of patients may be related to the decrease of autoreactive Th22 cell infiltration to neuromuscular junctions. However, the pathophysiologic role of Th22 cells in the pathogenesis of MG is not yet known, and further studies with large sample sizes are needed to establish the pathophysiologic role of IL-22 and Th22 cells in MG.

Furthermore, for the first time, the present study demonstrated the increased percentage of Tc22 in MG patients in comparison with HCs and significant decrease of these cells 6 months after TE. Also the Th22:Tc22 ratio in MG patients was significantly lower than in HCs. Tc22 are subsets of $\mathrm{CD} 8+\mathrm{T}$ cells, which are defined as CD8+IFN $\gamma$-IL-17-IL-22+ and the role of Tc22 in the pathogenesis of some autoimmune diseases such as MS and psoriasis has been indicated [24, 64]. Also, Czarnowicki et al. [24] indicated that in the atopic dermatitis CD8 $\mathrm{T}$ cells are a major source of IL-22, and they also found significant correlations between disease severity and CD8+IL-22+ T cells. Accordingly, our finding may implicate a role for Tc22 in MG pathogenesis, which warrants further research. Finally, although the exact mechanism by which TE ameliorates symptoms of MG is not yet clear, an explanation is that after TE the source of the autoreactive $\mathrm{T}$ cells will probably be removed.

\section{Conclusion}

We have provided some new insights into the frequency of Th22 and Tc22 in MG patients. To our knowledge, this is the first report to demonstrate an increased frequency of IL-22-producing CD8+ T cells in MG patients. In addition, our results show a decreased Th22 and Tc22 frequency post-TE. However, our study was limited by a small study population, short-term follow-up of patients (6 months), the absence of a pathophysiologic investigation of $\mathrm{T}$ cell transcription factors, and no data regarding cytokines. Larger scale studies are required to further clarify the role of these cells in MG pathogenesis.

\section{Acknowledgment}

This work was supported by the Isfahan University of Medical Sciences (grant No. 394392).

\section{Disclosure Statement}

The authors have no conflicts of interest related to this study.

\section{References}

1 Vincent A, Palace J, Hilton-Jones D: Myasthenia gravis. Lancet 2001;357:2122-2128.

2 Sommer N, Harcourt GC, Willcox N, Beeson D, Newsom-Davis J: Acetylcholine receptorreactive $\mathrm{T}$ lymphocytes from healthy subjects and myasthenia gravis patients. Neurology 1991;41:1270-1276.
3 Thomas CE, Mayer SA, Gungor Y, Swarup R, Webster EA, Chang I, et al: Myasthenic crisis: clinical features, mortality, complications, and risk factors for prolonged intubation. Neurology 1997;48:1253-1260.

4 Detterbeck FC, Scott WW, Howard JF, Egan TM, Keagy BA, Starek PJ, et al: One hundred consecutive thymectomies for myasthenia gravis. Ann Thorac Surg 1996;62:242-245.
5 Gajdos P: Intravenous immune globulin in myasthenia gravis. Clin Exp Immunol 1994; 97(suppl 1):49.

6 Baraka A, Taha S, Yazbeck V, Rizkallah P: Vecuronium block in the myasthenic patient: influence of anticholinesterase therapy. Anaesthesia 1993;48:588-590. 
7 Jaretzki A 3rd, Penn AS, Younger DS, Wolff M, Olarte MR, Lovelace RE, et al: "Maximal" thymectomy for myasthenia gravis: results. J Thorac Cardiovasc Surg 1988;95:747-757.

8 Blossom GB, Ernstoff RM, Howells GA, Bendick PJ, Glover JL: Thymectomy for myasthenia gravis. Arch Surg 1993;128:855-862.

9 von Boehmer $\mathrm{H}$, Kisielow P: Self-nonself discrimination by T cells. Science 1990;248: 1369-1373.

10 Gronseth GS, Barohn RJ: Practice parameter: thymectomy for autoimmune myasthenia gravis (an evidence-based review). Report of the Quality Standards Subcommittee of the American Academy of Neurology. Neurology 2000;55:7-15.

11 Williams CL, Lennon VA: Thymic B lymphocyte clones from patients with myasthenia gravis secrete monoclonal striational autoantibodies reacting with myosin, alpha actinin, or actin. J Exp Med 1986;164:1043-1059.

12 Mosmann TR, Coffman RL: TH1 and TH2 cells: different patterns of lymphokine secretion lead to different functional properties. Ann Rev Immunol 1989;7:145-173.

13 Annunziato F, Romagnani S: Heterogeneity of human effector CD4+ T cells. Arthritis Res Ther 2009;11:257.

14 Trifari S, Kaplan CD, Tran EH, Crellin NK, Spits H: Identification of a human helper T cell population that has abundant production of interleukin 22 and is distinct from $\mathrm{T}_{\mathrm{H}^{-}} 17$, $\mathrm{T}_{\mathrm{H}} 1$ and $\mathrm{T}_{\mathrm{H}} 2$ cells. Nat Immunol 2009;10: 864-871.

15 Duhen T, Geiger R, Jarrossay D, Lanzavecchia A, Sallusto F: Production of interleukin 22 but not interleukin 17 by a subset of human skinhoming memory T cells. Nat Immunol 2009; 10:857-863.

16 Zhang L, Li YG, Li YH, Qi L, Liu XG, Yuan $\mathrm{CZ}$, et al: Increased frequencies of Th22 cells as well as Th17 cells in the peripheral blood of patients with ankylosing spondylitis and rheumatoid arthritis. PLoS One 2012; 7:e31000

17 Piskin G, De Boer OJ, Van Der Loos CM, Teeling P, Bos JD, Teunissen MB: Overrepresentation of IL-17A and IL-22 producing $\mathrm{CD} 8 \mathrm{~T}$ cells in lesional skin suggests their involvement in the pathogenesis of psoriasis. PLoS One 2010;5:e14108.

18 Luan L, Ding Y, Han S, Zhang Z, Liu X: An increased proportion of circulating Th22 and Tc22 cells in psoriasis. Cell Immunol 2014; 290:196-200.

19 Guo H, Peng D, Yang XG, Wang Y, Xu BC, Ni JS, et al: A higher frequency of circulating IL$22^{+} \mathrm{CD}^{+} \mathrm{T}$ cells in Chinese patients with newly diagnosed Hashimoto's thyroiditis. PLoS One 2014;9:e84545.

20 Zhao R, Tang D, Yi S, Li W, Wu C, Lu Y, et al: Elevated peripheral frequencies of Th22 cells: a novel potent participant in obesity and type 2 diabetes. PLoS One 2014;9:e85770.
21 Xu W, Li R, Dai Y, Wu A, Wang H, Cheng C, et al: IL-22 secreting CD4+ T cells in the patients with neuromyelitis optica and multiple sclerosis. J Neuroimmunol 2013;261:87-91.

22 Vitales-Noyola M, Ramos-Levi AM, Martinez-Hernandez R, Serrano-Somavilla A, Sampedro-Nunez M, Gonzalez-Amaro R, et al: Pathogenic Th17 and Th22 cells are increased in patients with autoimmune thyroid disorders. Endocrine 2017;57:409-417.

23 Zhong W, Jiang Y, Ma H, Wu J, Jiang Z, Zhao L: Elevated levels of CCR6 ${ }^{+}$T helper 22 cells correlate with skin and renal impairment in systemic lupus erythematosus. Sci Rep 2017; 7:12962.

24 Czarnowicki T, Gonzalez J, Shemer A, Malajian $\mathrm{D}, \mathrm{Xu} \mathrm{H}$, Zheng X, et al: Severe atopic dermatitis is characterized by selective expansion of circulating TH2/TC2 and TH22/ TC22, but not TH17/TC17, cells within the skin-homing T-cell population. J Allergy Clin Immunol 2015;136:104-115.e7.

25 Hosseini M, Robat-Jazi B, Shaygannejad V, Naffisi S, Mirmossayeb O, Rezaei A, et al: Increased proportion of $\mathrm{Tc} 17$ and Th17 cells and their significant reduction after thymectomy may be related to disease progression in myasthenia gravis. Neuroimmunomodulation 2017;24:264-270.

26 Wang L, Zhang Y, He M: Clinical predictors for the prognosis of myasthenia gravis. BMC Neurol 2017;17:77.

27 Kang SY, Oh JH, Song SK, Lee JS, Choi JC, Kang JH: Both binding and blocking antibodies correlate with disease severity in myasthenia gravis. Neurol Sci 2015;36:1167-1171.

28 Berrih-Aknin S, Morel E, Raimond F, Safar D, Gaud C, Binet JP, et al: The role of the thymus in myasthenia gravis: immunohistological and immunological studies in 115 cases. Ann NY Acad Sci 1987;505:50-70.

29 Spillane J, Hayward M, Hirsch NP, Taylor C, Kullmann DM, Howard RS: Thymectomy: role in the treatment of myasthenia gravis. J Neurol 2013;260:1798-1801.

30 Le Panse R, Cizeron-Clairac G, Bismuth J, Berrih-Aknin S: Microarrays reveal distinct gene signatures in the thymus of seropositive and seronegative myasthenia gravis patients and the role of CC chemokine ligand 21 in thymic hyperplasia. J Immunol 2006; 177: 7868-7879.

31 Poea-Guyon S, Christadoss P, Le Panse R, Guyon T, De Baets M, Wakkach A, et al: Effects of cytokines on acetylcholine receptor expression: implications for myasthenia gravis. J Immunol 2005;174:5941-5949.

32 Shiono H, Roxanis I, Zhang W, Sims GP, Meager A, Jacobson LW, et al: Scenarios for autoimmunization of $\mathrm{T}$ and $\mathrm{B}$ cells in myasthenia gravis. Ann NY Acad Sci 2003;998: 237-256.

$33 \mathrm{Xu}$ WH, Zhang AM, Ren MS, Zhang XD, Wang F, Xu XC, et al: Changes of Treg-associated molecules on $\mathrm{CD} 4^{+} \mathrm{CD} 25^{+}$Treg cells in myasthenia gravis and effects of immunosuppressants. J Clin Immunol 2012;32:975-983.
34 Gradolatto A, Nazzal D, Truffault F, Bismuth J, Fadel E, Foti M, et al: Both Treg cells and Tconv cells are defective in the myasthenia gravis thymus: roles of IL-17 and TNF- $\alpha$. J Autoimmun 2014;52:53-63.

35 Ahlberg R, Yi Q, Pirskanen R, Matell G, Swerup C, Rieber EP, et al: Treatment of myasthenia gravis with anti-CD4 antibody: improvement correlates to decreased T-cell autoreactivity. Neurology 1994;44:1732-1737.

36 Morgutti M, Conti-Tronconi BM, Sghirlanzoni A, Clementi F: Cellular immune response to acetylcholine receptor in myasthenia gravis: II. Thymectomy and corticosteroids. Neurology 1979;29:734-738.

37 Nath A, Kerman RH, Novak IS, Wolinsky JS Immune studies in human immunodeficiency virus infection with myasthenia gravis: a case report. Neurology 1990;40:581-583.

38 Buckley C, Douek D, Newsom-Davis J, Vincent A, Willcox N: Mature, long-lived CD4+ and CD8+ T cells are generated by the thymoma in myasthenia gravis. Ann Neurol 2001;50:64-72.

39 Strobel P, Preisshofen T, Helmreich $\mathrm{M}$, Muller-Hermelink HK, Marx A: Pathomechanisms of paraneoplastic myasthenia gravis. Clin Dev Immunol 2003;10:7-12.

40 Ji Q, Castelli L, Goverman JM: MHC class Irestricted myelin epitopes are cross-presented by Tip-DCs that promote determinant spreading to $\mathrm{CD}^{+} \mathrm{T}$ cells. Nat Immunol 2013; 14:254-261

41 Friese MA, Jakobsen KB, Friis L, Etzensperger $\mathrm{R}$, Craner MJ, McMahon RM, et al: Opposing effects of HLA class I molecules in tuning autoreactive CD8+ T cells in multiple sclerosis. Nat Med 2008;14:1227-1235.

42 Tackenberg B, Schlegel K, Happel M, Eienbroker C, Gellert K, Oertel WH, et al: Expanded TCR V $\beta$ subsets of $C D 8^{+}$T-cells in lateonset myasthenia gravis: novel parallels with thymoma patients. J Neuroimmunol 2009; 216:85-91.

43 Vitales-Noyola M, Ramos-Levi AM, Martinez-Hernandez R, Serrano-Somavilla A, Sampedro-Nunez M, Gonzalez-Amaro R, et al: Pathogenic Th17 and Th22 cells are increased in patients with autoimmune thyroid disorders. Endocrine 2017;57:409-417.

44 Ryba-Stanislawowska M, Werner P, Brandt A, Mysliwiec M, Mysliwska J: Th9 and Th22 immune response in young patients with type 1 diabetes. Immunol Res 2016;64:730-735.

45 Kagami S, Rizzo HL, Lee JJ, Koguchi Y, Blauvelt A: Circulating Th17, Th22, and Th1 cells are increased in psoriasis. J Invest Dermatol 2010;130:1373-1383.

46 Liu T, Peng L, Yu P, Zhao Y, Shi Y, Mao X, et al: Increased circulating Th22 and Th17 cells are associated with tumor progression and patient survival in human gastric cancer. J Clin Immunol 2012;32:1332-1339.
High Frequency of Tc22 and Th22 Cells in Myasthenia Gravis Patients
Neuroimmunomodulation 2018;25:80-88 
47 Truchetet M-E, Brembilla NC, Montanari E, Allanore Y, Chizzolini C: Increased frequency of circulating Th22 in addition to Th17 and Th2 lymphocytes in systemic sclerosis: association with interstitial lung disease. Arthritis Res Ther 2011;13:R166.

48 Gradolatto A, Nazzal D, Foti M, Bismuth J, Truffault F, Le Panse R, et al: Defects of immunoregulatory mechanisms in myasthenia gravis: role of IL-17. Ann NY Acad Sci 2012; 1274:40-47.

49 Zheng S, Dou C, Xin N, Wang J, Wang J, Li P, et al: Expression of interleukin-22 in myasthenia gravis. Scand J Immunol 2013;78:98-107.

50 Zenewicz LA, Yancopoulos GD, Valenzuela DM, Murphy AJ, Karow M, Flavell RA: Interleukin-22 but not interleukin-17 provides protection to hepatocytes during acute liver inflammation. Immunity 2007;27:647-659.

51 Zheng Y, Danilenko DM, Valdez P, Kasman $\mathrm{I}$, Eastham-Anderson J, Wu J, et al: Interleukin-22, a $\mathrm{T}_{\mathrm{H}} 17$ cytokine, mediates IL-23-induced dermal inflammation and acanthosis. Nature 2007;445:648-651.

52 Qin S, Ma S, Huang X, Lu D, Zhou Y, Jiang H: Th22 cells are associated with hepatocellular carcinoma development and progression. Chin J Cancer Res 2014;26:135-141.
53 Chen P, Wang M, Li D, Jia Y, He N, Li W, et al: The alteration and clinical significance of Th22/Th17/Th1 cells in patients with chronic myeloid leukemia. J Immunol Res 2015;2015: 416123.

54 Deniz R, Tulunay-Virlan A, Ture Ozdemir F, Unal AU, Ozen G, Alibaz-Oner F, et al: Th17inducing conditions lead to in vitro activation of both Th17 and Th1 responses in Behcet's disease. Immunol Invest 2017;46:518-525.

55 Aktas Cetin E, Cosan F, Cefle A, Deniz G: IL22 -secreting Th22 and IFN- $\gamma$-secreting Th17 cells in Behcet's disease. Mod Rheumatol 2014;24:802-807.

56 Benham H, Norris P, Goodall J, Wechalekar MD, FitzGerald O, Szentpetery A, et al: Th17 and Th22 cells in psoriatic arthritis and psoriasis. Arthritis Res Ther 2013;15:R136

57 Zhang X, Liu S, Chang T, Xu J, Zhang C, Tian $\mathrm{F}$, et al: Intrathymic $\mathrm{Tfh} / \mathrm{B}$ cells interaction leads to ectopic GCs formation and antiAChR antibody production: central role in triggering MG occurrence. Mol Neurobiol 2016;53:120-131.

58 Leite MI, Strobel P, Jones M, Micklem K, Moritz R, Gold R, et al: Fewer thymic changes in MuSK antibody-positive than in MuSK antibody-negative MG. Ann Neurol 2005;57: 444-448.
59 Lauriola L, Ranelletti F, Maggiano N, Guerriero $\mathrm{M}$, Punzi $\mathrm{C}$, Marsili $\mathrm{F}$, et al: Thymus changes in anti-MuSK-positive and -negative myasthenia gravis. Neurology 2005;64:536538

60 Hosseini M, Robat-Jazi B, Shaygannejad V, Naffisi S, Mirmossayeb O, Rezaei A, et al: Increased proportion of Tc17 and Th17 cells and their significant reduction after thymectomy may be related to disease progression in myasthenia gravis. Neuroimmunomodulation 2017;24:264-270.

61 Duhen T, Geiger R, Jarrossay D, Lanzavecchia A, Sallusto F: Production of interleukin 22 but not interleukin 17 by a subset of human skinhoming memory T cells. Nat Immunol 2009; 10:857-863.

62 Mahnke YD, Beddall MH, Roederer M: OMIP-017: human $\mathrm{CD}^{+}$helper T-cell subsets including follicular helper cells. Cytometry A 2013;83:439-440.

63 Fujita H: The role of IL-22 and Th22 cells in human skin diseases. J Dermatol Sci 2013;72: 3-8.

64 Aboseif SR, Breza J, Bosch RJ, Benard F, Stief CG, Stackl W, et al: Local and systemic effects of chronic intracavernous injection of papaverine, prostaglandin $\mathrm{E} 1$, and saline in primates. J Urol 1989;142:403-408. 